\title{
sciendo
}

\section{Sleep Patterns and Alertness in an Elite Super Rugby Team During a Game Week}

\author{
by \\ Ian C Dunican ${ }^{1}$, Charles C Higgin ${ }^{2}$, Kevin Murray ${ }^{3}$, Maddison J Jones 4 , \\ Brian Dawson ${ }^{4}$, John A Caldwell ${ }^{5}$, Shona L Halson ${ }^{6}$, Peter R Eastwood ${ }^{1}$
}

\begin{abstract}
Sleep is a vital component of preparation, performance and recovery for a Super Rugby game. The purpose of this study was to quantify sleep behaviours and alertness of professional rugby union players during training and a game. Thirty-six rugby union players from a Super Rugby team wore a wrist-activity device (Readiband ${ }^{\mathrm{TM}}$ ) to measure sleep for 3 days before, 3 days after and on the night of an evening game. Players were separated into those selected to play the game $(n=23)$ and those who were not $(n=13)$. Alertness was assessed for all training and game times using bio-mathematical modelling. Alertness measures $\leq 90 \%$ were considered to reflect impaired reaction time. Those selected to play in the game progressively increased sleep duration over the nights prior to the game (by 92 min $p \leq 0.05$ ) by delaying wake time. Players went to bed later after the game (02:20 \pm 114 min vs $22: 57 \pm 60$ min; $p \leq 0.001)$ which resulted in decreased sleep duration on game night compared to pre-game nights ( $296 \pm 179$ min vs $459 \pm 78$ min; $p \leq$ 0.05). Four players did not achieve any sleep on game night. Sleep duration appeared to be truncated by early morning training sessions (before 08:00) on the second and third mornings after the game. Alertness was $>90 \%$ for all training and game times for all players. In conclusion, in the days leading into a Super Rugby game, players delay morning time at wake and consequently increase sleep duration with post-game sleep reduced in some.
\end{abstract}

Key words: alertness, recovery, actigraphy, athletes.

\section{Introduction}

A rugby union game lasts for $80 \mathrm{~min}$ and is cognitively and physically demanding. Throughout the game, effective decision making and execution of game-specific strategies are required (Fullagar et al., 2015). Previously, most rugby (union and league) studies have examined how to optimise player performance by focusing on improving position-dependent physical attributes, such as mass and body fat, endocrine levels and power output (Duthie et al., 2003; Kilduff et al., 2015; Shearer et al., 2015). However, sleep is vital in the recovery and performanceof athletes (Gupta et al., 2016). Studies in other team sports such as rugby league (Thornton et al., 2017) and soccer (Fullagar et al., 2016) highlight this importance, yet little is known about sleep behaviours of elite rugby players (Dunican and Eastwood, 2016). To date, only two studies have reported the effects of training and game time on sleep in rugby union players; both utilised wristactivity monitors to assess sleep on the nights before, the night of and nights after a game, reporting increases in player sleep duration in the nights prior to a game, and delayed sleep onset

\footnotetext{
1 - Centre for Sleep Science, School of Huma Sciences, The University of Western Australia, Crawley, WA 6009, Australia.

2 - Western Force, Rugby Western Australia, Floreat WA 6014, Australia.

3 - School of Population and Global Health, The University of Western Australia, Crawley, WA 6009, Australia.

4 - School of Human Sciences, The University of Western Australia, Crawley, WA 6009, Australia.

5 - Coastal Performance Consulting, Florida, United States.

6 - Department of Physiology, Australian Institute of Sport, Leverrier Street, Bruce, ACT, 2617, Australia.
} 
time and decreased sleep duration on the night of the game (Eagles et al., 2014; Shearer et al., 2015).

The present study used wrist-activity monitors to assess sleep in elite rugby players as they minimally interfere with normal training and sleep in athletes (Lee, 2012). This study also estimated alertness during training and game time via a three process bio-mathematical model (Borbely, 1982), the Sleep, Activity, Fatigue and Task Effectiveness (SAFTE) model (Hursh, 2004). This approach is common in military, aviation and railroad operations in the design of work and rest patterns to maximise alertness and to minimise risk (Dean et al., 2007; Hilaire and Klerman, 2007). To date, no studies have investigated the use of such bio-mathematical modelling in athletic populations to assess alertness.

Typically, during the week of a Super Rugby game, a team of 23 players (15 to start the game, plus 8 substitutes) are selected from a squad of 36 players three days prior to a game. The remaining players (13) continue to train with the team up to the day before the game. At present, very little is known about sleep patterns and their relationship to player alertness in the days leading into a competitive game. Such information could be beneficial to coaches and researchers in understanding pre-game, and postgame sleep behaviours that may be used to support the scheduling of training times to optimise recovery and alertness.

These circumstances provide a unique opportunity to investigate the sleep habits of those selected (and not selected) to play the game and thereby understand more about the sleep behaviours of elite rugby players before and after training and game periods. Therefore, the aims of this study were to: (i) quantify the differences in sleep behaviours in players who played the game and those from the greater squad who did not play during the week of a Super Rugby home game; and (ii) estimate alertness for players in both groups for training and game time.

\section{Methods}

\section{Participants}

Thirty-six elite contracted male rugby union players from a Super Rugby team based in Perth, Western Australia participated in this study. Players age was $26 \pm 3$ years (21-34 years) and body mass $102 \pm 11 \mathrm{~kg}$ (80-122 kg). Demographic information, health status and sleep history were collected from players via a paperbased survey. Ethics approval was obtained (RA/4/1/7235) and informed consent received from all athletes prior to participation. This study was conducted in compliance with the Declaration of Helsinki for human experimentation.

\section{Measures}

Measures of sleep were obtained from a wrist-activity monitor, the Readiband ${ }^{\mathrm{TM}}$ (v3, analysed using Readiband $\mathrm{Sync}^{\mathrm{TM}}$ ) (Fatigue Science Inc., Canada). The wrist-activity monitor was issued to each player at 17:00 on the Wednesday; three days before the game and collected at 08:00 on the Wednesday; four days after the game. These were continuously worn on the non-dominant wrist throughout the 7-day period. The Readiband has good validity (overall accuracy of $93 \%$ ) when compared to sleep/wake epochs against polysomnography (Russell, 2006), has undergone in-field validation in Australian Rules Football (Dennis et al., 2016) and has been approved by the US Federal Drug Administration (FDA) (Readiband FDA Approval, 2011) as a device for measurement of physical activity and sleep data.

The monitors were downloaded and analysed using the automated Readiband Sync software and its proprietary algorithm. The proprietary algorithm has been shown to compare favourably both to in-laboratory polysomnography (PSG) and another widely used and validated wrist-activity monitor, the ActiGraph device (Dunican et al., 2017). Sleep measures derived included: time at sleep onset (the time the person initiated sleep), sleep latency (time between lights out and sleep onset), sleep duration (time between sleep onset and wake, minus any time awake during this period), wake after sleep onset (WASO) (time spent awake after sleep onset and before final waking time), time at wake (time of final waking, not followed by any additional sleep) and sleep efficiency (percentage of time spent asleep whilst in bed: sleep duration/time in bed minus sleep latency and WASO).

Measures of alertness were calculated using the SAFTE algorithm. SAFTE incorporates a homeostatic sleep reservoir, circadian oscillator 
and sleep inertia function (Roma, 2012) to generate a measure of alertness (Hursh, 2004). The SAFTE algorithm interface allows the input of variables such as geographical location (longitude and latitude) for the calculation of natural light and dark cycles of that specific location, as these will affect the circadian rhythm of persons in that location, duration of training sessions (e.g. 09:0012:00 and 13:00-15:00) as provided by the athletic staff, and sleep variables from the activity monitors as collected via the Readiband during this study (Balkin et al., 2000). These variables provide a measures of alertness derived from the SAFTE algorithm and have been correlated with and validated against the psychomotor-vigilance test (PVT) $\left(\mathrm{R}^{2}=0.88, p \leq 0.001\right)$ (Balkin et al., 2000; Roma et al., 2012), such that the greater the alertness score the less the likelihood of lapses in reaction time. The PVT is a $10 \mathrm{~min}$ test in duration, requiring participants to respond to an on-screen stimulus as quickly as possible with a new stimulus appearing randomly every 2-10 s. This test has been used to monitor vigilant attention decrements caused by fatigue or sleep loss (Basner and Dinges, 2011; Van Dongen et al., 2003). In our study, the SAFTE model was used to generate a continuous estimate (scale from 0$100 \%$ ) of alertness for each player across 7 days. Ideally, individuals and teams should be training and competing when alertness is maximal $>90 \%$. Please see the notes section of Figure 1 for more detail about the SAFTE model.

This study was based around an evening home game (19:00-21:00) in the Super Rugby competition during April 2015. This game was selected as no travel occurred for 13 days prior to, or 10 days after the game. Consequently, players had access to their usual home sleeping environment and performance was unaffected by travel across time zones. Continuous sleep measurements were obtained on each player over a 7-night period: pre-game (Wednesday, Thursday and Friday), the night of the game (Saturday) and post-game (Sunday, Monday, Tuesday). For data analysis, the 36 players were separated into those selected to play in the game (Game-Group, $\mathrm{n}=23$ ) and those not selected (NonGame Group, $\mathrm{n}=13$ ). Selection by the Head Coach was made on the Thursday prior to the game, and all players in the Non-Game Group attended the game as spectators.

\section{Statistical analysis}

Comparisons of demographics and sleep history measures were made between the two groups (Game-Group ws Non-Game Group) using two-sample t-tests. The 7-day study period was separated into pre-game nights $(1,2$ and 3$)$, game night, and post-game nights (1,2 and 3$)$. Linear mixed models were used to compare wristactivity monitor sleep measures between the two groups (Game-Group vs Non-Game Group) over the 7 nights of the study. The models included fixed effects of group (Game-Group vs Non-Game Group) and night (1 to 7 ), their interaction and random effect of the individual. Differences in least squares means were used to determine statistically significant differences after observing significant fixed effects and estimates of these differences along with $95 \%$ confidence intervals (CIs). Data are presented as mean \pm standard deviation (SD) unless otherwise stated with $p \leq 0.05$ considered statistically significant for all tests. All analyses were carried out using the $R$ environment for statistical computing (R-Core Team, 2016 ).

\section{Results}

In the Game-Group, 3 players were excluded from the final analyses due to their failure to consistently wear the wrist-activity monitor, meaning data from 33 players were analysed (Game-Group, 20; Non-Game Group, 13).

\section{Demographic information and sleep history}

Demographic, anthropometric measures and sleep history were similar between groups (Table 1). The number of days with disrupted sleep during the week was greater in the NonGame Group by $2 \pm 1$ days compared to the GameGroup $(p \leq 0.05)$.

\section{Overall sleep measures (both groups)}

Considering the entire squad $(n=33)$ there was: a later time of sleep onset ( $\sim 3 \mathrm{hrs})$ on the night of the game relative to all nights before and after the game; a tendency to progressively wake later leading up to a game ( $2 \mathrm{hrs})$; and a progressive increase in sleep duration on the days leading up to a game ( 1.5 hrs). 


\begin{tabular}{|c|c|c|}
\hline \multicolumn{3}{|c|}{$\begin{array}{c}\text { Table } \mathbf{1} \\
\text { Descriptive characteristics (mean } \pm S D \text { or counts) of Game vs Non-Game Group }\end{array}$} \\
\hline & $\begin{array}{c}\text { Game } \\
(\mathrm{n}=20)\end{array}$ & $\begin{array}{c}\text { Non- } \\
\text { Game } \\
(\mathrm{n}=13)\end{array}$ \\
\hline \multicolumn{3}{|l|}{ Demographic information } \\
\hline Age (years) & $26 \pm 3$ & $25 \pm 3$ \\
\hline Body Mass (kg) & $102 \pm 12$ & $102 \pm 10$ \\
\hline Height $(\mathrm{cm})$ & $185 \pm 7$ & $185 \pm 8$ \\
\hline Body Mass Index (BMI) & $30 \pm 3$ & $30 \pm 2$ \\
\hline Neck size $(\mathrm{cm})$ & $41 \pm 6$ & $45 \pm 2$ \\
\hline \multicolumn{3}{|l|}{ Sleep history } \\
\hline Sleep you feel you need each night (min) & $433 \pm 52$ & $431 \pm 56$ \\
\hline Sleep you get each night (min) & $426 \pm 60$ & $420 \pm 58$ \\
\hline \multirow[t]{2}{*}{ Sleep you feel you need after training or competition (mins) } & $465 \pm 92$ & $474 \pm 72$ \\
\hline & $348 \pm$ & \\
\hline Sleep you get after training or competition (mins) & & $370 \pm 122$ \\
\hline Number of days disrupted sleep per week (count) & $2 \pm 2^{*}$ & $4 \pm 1$ \\
\hline Number of times sleep is disrupted each night (count) & $2 \pm 1$ & $1 \pm 1$ \\
\hline \multicolumn{3}{|c|}{ How would you rate the importance of sleep on your recovery (count of response) } \\
\hline Not important at all & - & - \\
\hline Somewhat important & 1 & 1 \\
\hline Important & 6 & 5 \\
\hline Extremely important & 9 & 7 \\
\hline \multicolumn{3}{|l|}{ Self-reported health status (count of response) } \\
\hline Excellent & 4 & 3 \\
\hline Very Good & 10 & 5 \\
\hline Good & 2 & 2 \\
\hline \multicolumn{3}{|l|}{ Martial and family status (count of response) } \\
\hline Married & 2 & 2 \\
\hline Single & 9 & 3 \\
\hline Living with a partner & 5 & 3 \\
\hline Number of players with children under 18 (living at home) & 4 & 4 \\
\hline $\begin{array}{l}\text { Anthropometric data and sleep-related responses from the survey instrumer } \\
\text { presented as means and standard deviations (SD). }{ }^{*} p<0.05 \text { for Game-Group } \\
\text { Group. }\end{array}$ & $\begin{array}{l}\text { Data ar } \\
\text { Non-Ga }\end{array}$ & \\
\hline
\end{tabular}




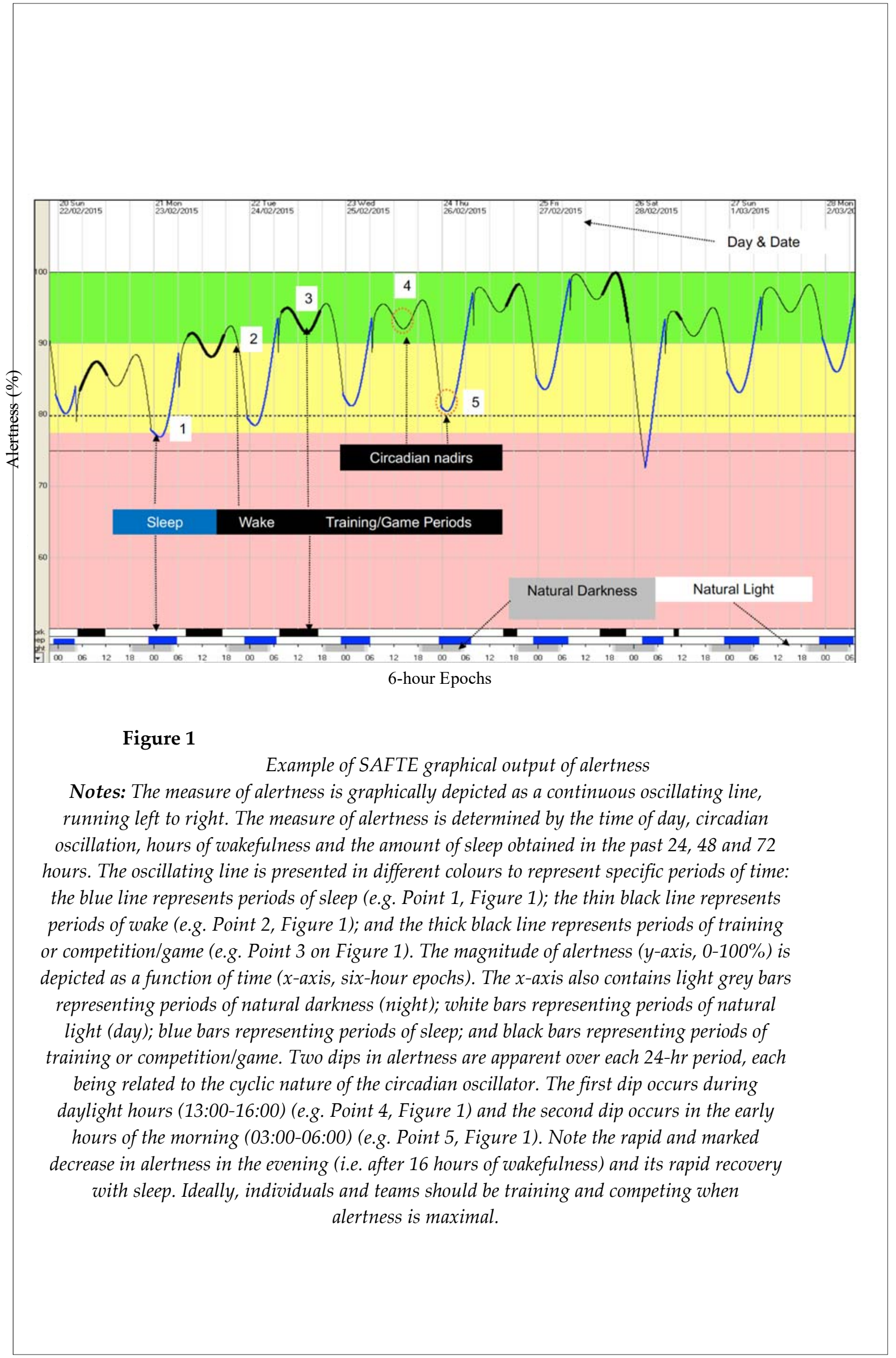




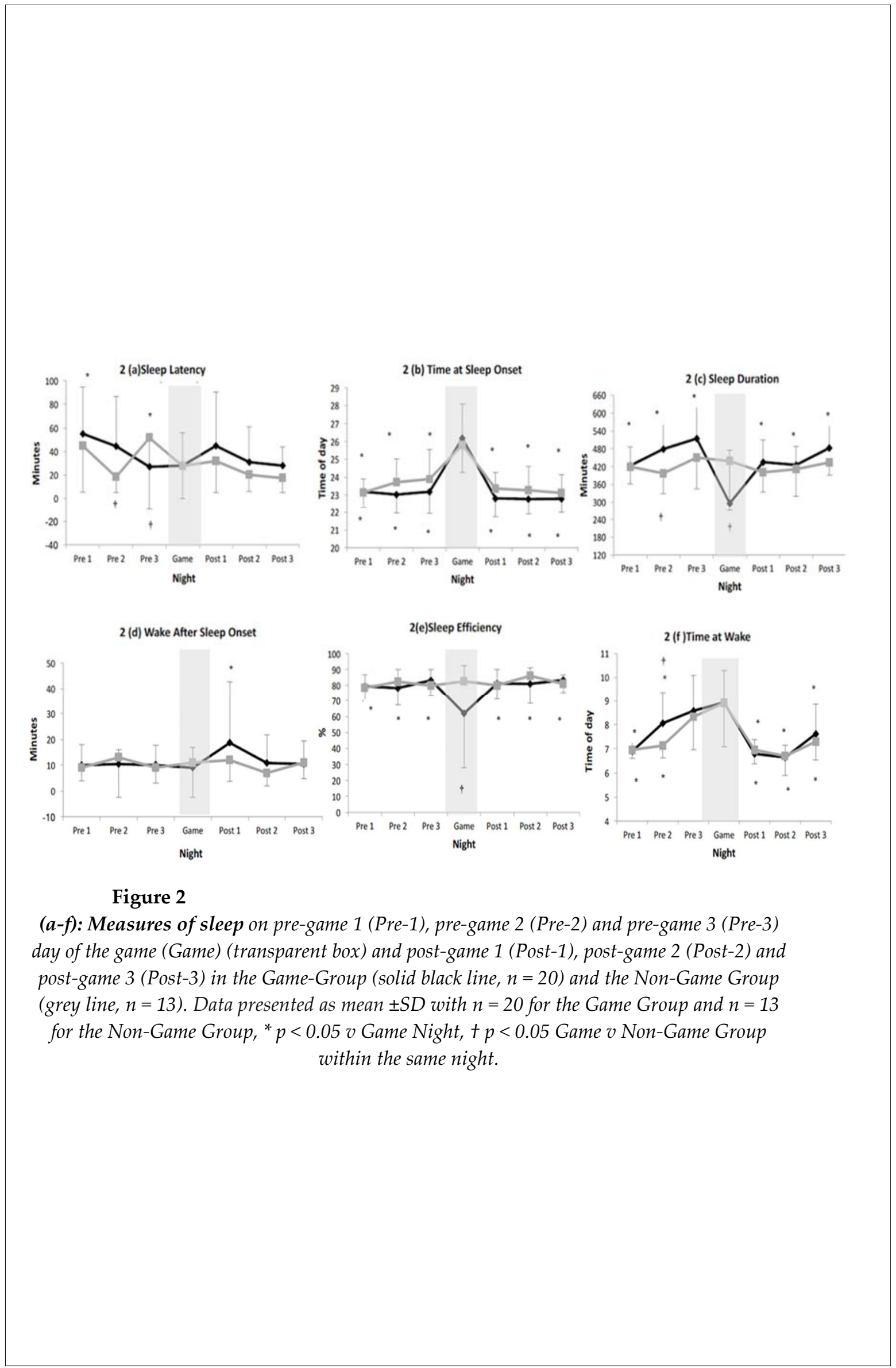



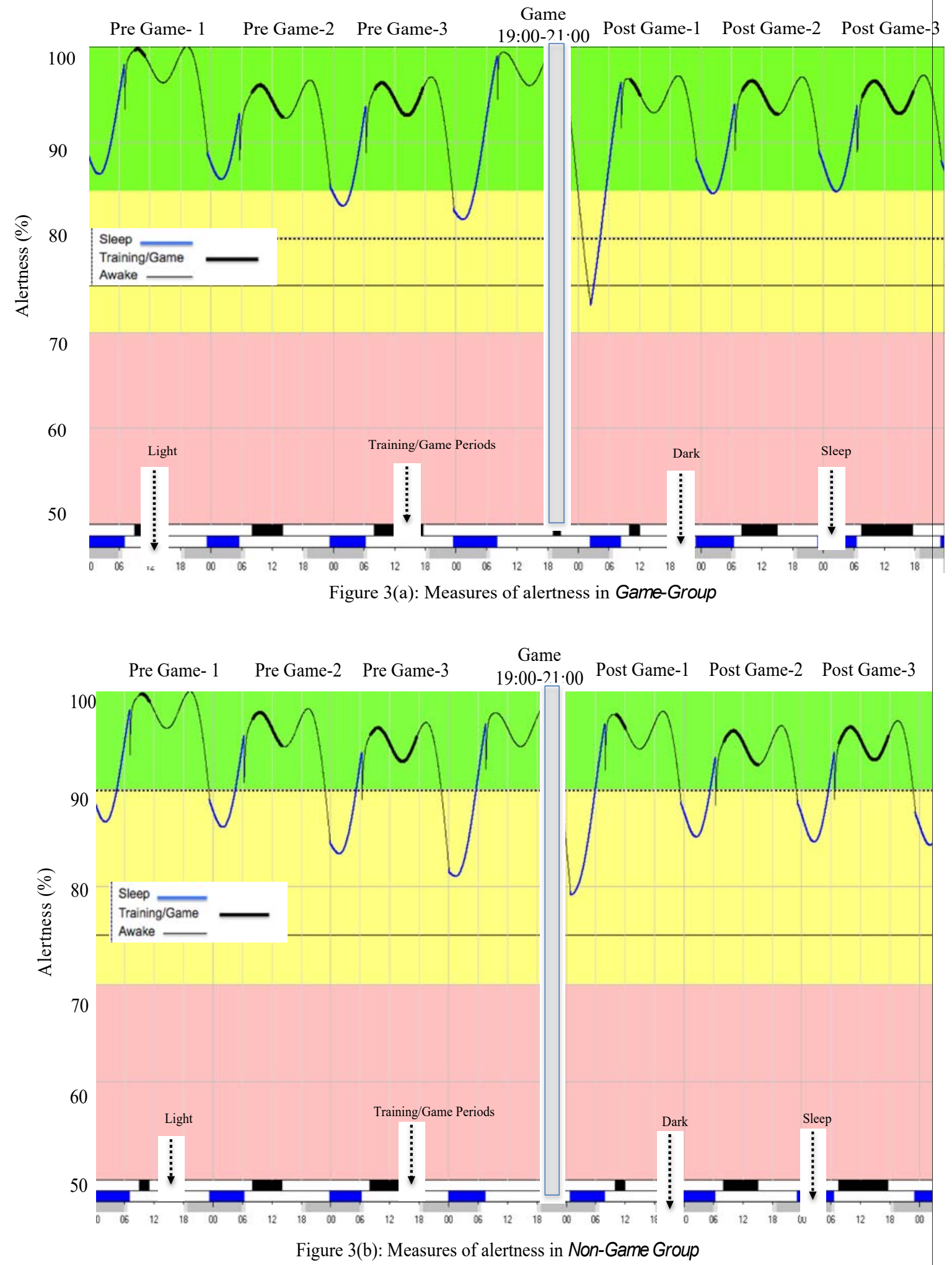

Figure 3

(a-b): Measures of alertness on pre-game 1, pre-game 2 and pre-game 3, the night of the game (Game) (transparent box) and post-game 1, post-game 2 and post-game 3 for both the Game-Group (a) and the Non-Game Group (b). 


\section{Discussion}

This study found that professional rugby players, those who were selected to play (compared to those not selected but who still attended the game), progressively increased sleep duration in the nights leading into an evening game. Those who played went to bed $3 \mathrm{hrs}$ later on the night of the game (02:00 vs 23:00 hrs on other nights), with a resultant decrease in sleep duration of $\sim 2.5 \mathrm{hrs}$ on this night. These changes in sleep did not affect the modelled estimate of alertness, which remained above $93 \%$ of maximum during the game and all training sessions.

The progressive increase in sleep duration seen in the nights leading into an evening game has also been reported in two other rugby studies (Eagles et al., 2014; Shearer et al., 2015) and may represent an intentional pre-game strategy by athletes to optimise game performance. Our study shows that such sleep behaviours occur only in those players selected to play, and not in unselected players who attended the game as spectators. While the precise performance benefits of increases in sleep duration remain unclear, a previous study of prolonged periods of sleep extension in collegiate basketball players resulted in improved sprint times, shooting accuracy, reaction time and levels of daytime sleepiness (Mah et al., 2011). Similar sleep prolongation strategies are employed in military special operations by the intentional provision of extended sleep opportunities prior to deployment on missions (Yarnell and Deuster, 2016).

In contrast to the nights leading into a game, which were characterised by a progressive increase in sleep duration, on the game night, those who played the game had a 2.5-hr decrease in sleep duration. This was primarily due to a 3-hr delay in sleep onset time compared to all other nights. Such findings are consistent with results from other studies conducted in rugby union and the Australian Football League; after evening games, sleep onset time was delayed and sleep duration reduced compared to pre-game nights (Lastella et al., 2015; Sargent and Roach, 2016; Shearer et al., 2015). The delay in time to sleep following a game could be due to several factors, including media commitments, recovery sessions, socialising, persisting game-related increases in cortisol levels and mood disturbances, both of which can occur for 12-36 hrs after a rugby game (West et al., 2014) and up to $48 \mathrm{hrs}$ following a rugby league game (McLellan et al., 2011). It was of interest that four players did not achieve any sleep after the game. The self-reported reasons for this included the effects of post-game arousal, the stress of having lost the game, and engagement in post-game socialising with other team members.

The mechanisms underlying the significant increase in time at sleep onset following an evening game still remain unclear but could include the potentially detrimental effects of pre-game ergogenic caffeine ingestion on sleep.

The nights following the game were characterised by a gradual return to pre-game sleep patterns. On the second and third nights, post-game wake times were constrained by scheduled early morning training sessions (commencing before 08:00). These early morning training sessions truncate the opportunity for sleep, thus reducing sleep duration (Dunican et al., 2017).

As previously noted, the measure of alertness used in this study has been validated against the PVT ( $22=0.88, \mathrm{p} \leq 0.001)($ Roma, 2012; Van Dongen, 2004), a test of sustained attention that is sensitive to sleep loss (Dawson and Reid, 1997) and circadian misalignment and which provides a surrogate measure of behavioural alertness (Van Dongen, 2004). The alertness algorithm and association with PVT has been validated in both the aviation and rail transportation industries (Hursh et al., 2006; Roma et al., 2012) such that values of alertness $\leq 90 \%$ are considered to reflect impaired reaction times. Indeed, alertness values between $80-90 \%$ have been associated with an $18 \%$ decrease in reaction time based upon PVT results and an alertness score of $77 \%$ has been shown to be accompanied by a $34 \%$ reduction in reaction time (Hursh et al., 2006; Roma et al., 2012), the latter decrease in reaction time being equivalent to that occurring with blood alcohol concentration of $0.05 \%$ or after $17 \mathrm{hrs}$ of sustained wakefulness (Dawson and Reid, 1997). While there are no published reports of alertness being used in athletic populations, such information may be useful for identifying periods of cognitive impairment, which may result in suboptimal performance. 
In the present study for both the Game and Non-Group players, alertness remained $>90 \%$ during all training sessions and $>95 \%$ during the game. The tendency for game alertness to increase might be attributable to increased sleep in the days before the game, particularly in those players who were selected to participate in the evening game. Potentially, substantial differences in alertness could occur with international travel, which occurs regularly with Super Rugby teams. By adjusting for changes in time zones, the SAFTE model used in this study (Hursh et al., 2004) and other bio-mathematical models could be used to predict optimal travel and training times for travelling teams.

\section{Limitations}

The sample size in this study was limited by squad numbers $(n=36)$, as this was the only team based within the State. However, the data collected reflect the responses of the whole team, thus the findings are representative of sleep in elite rugby players within a Super Rugby team. Also, the results relate to a single Super Rugby home game with no interstate or international travel in the week before or after, as such it is not known how representative they are of other teams, especially following travel to away games.

\section{Conclusions}

Those professional rugby players who were selected during the week to play in an evening game on the weekend showed a progressive increase in sleep duration in the days leading up to the game. It is possible that such behaviour is an attempt by the player to maximise alertness for training and game time, which were high in the Game-Group. However, it was notable that high levels of alertness were also observed in those players who were not selected to play in the weekend game, suggesting that they might be prepared, at least in terms of alertness, for lastminute inclusion in the team on the game day if needed. The finding of a significant delay in time of sleep onset and reduction in sleep duration after a game in all players should be of interest to coaches, who could consider delaying post-game training sessions to allow for optimal recovery. Bio-mathematical modelling of alertness, as used in this study, may represent a useful tool for coaching and performance staff for the development of objective performance decisions related to training and recovery periods. Such modelling could, for example, be used to assist with scheduling of travel.

\section{Acknowledgements}

Many thanks to Fatigue Science, Vancouver, British Columbia for the supply of Readiband ${ }^{\mathrm{TM}}$ and SAFTE ${ }^{\mathrm{TM}}$ software and to the staff and players at the Western Force. Peter R Eastwood is supported by an NHMRC Senior Research Fellowship (No. 513704).

\section{References}

Balkin TJ, Thorne D, Sing H, Thomas M, Redmond DP, Wesensten NJ, Belenky G. Effects of Sleep Schedules on Commerical Motor Vehicle Driver Performance. Dept of Transportation, Federal Motor Carrier Safety Administration, 2000; DOT-MC-00-133, Available at https://ntl.bts.gov/lib/11000/11100/11127/ESS.pdf, accessed on 17.04.2017

Basner M, Dinges DF. Maximizing sensitivity of the psychomotor vigilance test (PVT) to sleep loss. Sleep, 2011; 34(5): 581-591

Borbely AA. A two process model of sleep regulation. Hum Neurobiol, 1982; 1(3): 195-204

Dawson D, Reid K. Fatigue, alcohol and performance impairment. Nature, 1997; 388(6639): 235

Dean DA II, Fletcher A, Hursh SR, Klerman EB. Developing mathematical models of neurobehavioral performance for the "real world". J Biol Rhythm, 2007; 22(3): 246+

Dennis J, Dawson B, Heasman J, Rogalski B, Robey E. Sleep patterns and injury occurrence in elite Australian footballers. J Sci Med Sport, 2016; 19(2): 113-116

Dunican IC, Eastwood PR. Sleep is an important factor when considering rugby union player load. $\mathrm{Br} \mathrm{J}$ Sports Med, 2017; 51: 1640 
Dunican IC, Martin DT, Halson SL, Reale R, Dawson B, Caldwell J, Jones MJ, Eastwood PR. The Effects of the Removal of Electronic Devices for 48 hours on Sleep in Elite Judo Athletes. J Strength Cond Res, 2017; 31(10): 2832-2839

Dunican IC, Murray K, Slater JA, Maddison KJ, Jones MJ, Dawson B, Straker LM, Caldwell JA, Halson SL, Eastwood PR. Laboratory and home comparison of wrist-activity monitors and polysomnography in middle-aged adults. Sleep Biol. Rhythms, 2018; 16(1): 85-97

Duthie G, Pyne D, Hooper S. Applied physiology and game analysis of rugby union. Sports Med, 2003; 33(13): 973-991

Eagles A, McLellan C, Hing W, Carloss N, Lovell, D. Changes in sleep quantity and efficiency in professional rugby union players during home based training and match-play. J Sports Med Phys Fitness, 2014; 56(5): 565-571

Fullagar HH, Skorski S, Duffield R, Hammes D, Coutts AJ, Meyer T. Sleep and athletic performance: the effects of sleep loss on exercise performance, and physiological and cognitive responses to exercise. Sports Med, 2015; 45(2):161-186

Fullagar HH, Skorski S, Duffield R, Julian R, Bartlett J, Meyer T. Impaired sleep and recovery after night matches in elite football players. J Sports Sci, 2016; 34(14): 1333-1339

Gupta L, Morgan K, Gilchrist S. Does Elite Sport Degrade Sleep Quality? A Systematic Review. Sports Med, 2016; 47(7): 1317-1333

Hilaire MS, Klerman EB. On mathematical modeling of circadian rhythms, performance, and alertness. J of Biol Rhythm, 2007; 22(2): 91+

Kilduff LP, Cook CJ, Shearer DA. Special issue: Science and rugby. Eur J Sport Sci, 2015; 15(6): 459

Lastella M, Roach GD, Halson SL, Sargent C. Sleep/wake behaviours of elite athletes from individual and team sports. Eur J Sport Sci, 2015; 15(2): 94-100

Lee SJ. What is Actigraphy? Amercian Academy of Sleep Technologists, Wolters Kluwer ,Lippincott Williams \& Wilins, Chapter 41 Actigraphy; 2012

Mah CD, Mah KE, Kezirian EJ, Dement WC. The effects of sleep extension on the athletic performance of collegiate basketball players. Sleep, 2011; 34(7): 943-950

R-Core Team. R: A language and environment for statistical computing. R Foundation for Statistical Computing, Vienna, Austria, 2016; available at http://www.R-project.org/ accessed on 4.02.2017

McLellan CP, Lovell DI, Gass GC. Markers of postmatch fatigue in professional Rugby League players. J Strength Cond Res, 2011; 25(4): 1030-1039

Readiband FDA Approval, F. S. FDA Approval for Readiband-K111514 -SBV2. Federal Drug Administration Federal Drug Administration, 2011;

Available at http://www.accessdata.fda.gov/cdrh_docs/pdf11/k111514.pdf ; accessed 10.08.2017

Roma PH, Mead A, Nesthus T. Flight Attendant Work/Rest Patterns, Alertness, and Performance Assessment: Field Validation of Biomathematical Fatigue Modeling. Office of Aerospace Medicine Federal Aviation Administration 800 Independence Ave., S.W. Washington, DC 20591, 2012; DOT/FAA/AM-12/12. Available: at https:/www.icao.int/safety/airnavigation/OPS/CabinSafety/Cabin\%20Safety\%20Library/

Russell CA, Arand D, Myers LJ, Wubbels P, Downs H. Controlling fatigue risk with the Fatigue Science ReadiBand actigraph and associated sleep/wake classification algorithms: use case and validation. 2006; Available at https://www.fatiguescience.com/wp-content/uploads/2016/09/ReadibandValidation-Accuracy.pdf; accessed 10.08.2017

Sargent C, Roach GD. Sleep duration is reduced in elite athletes following night-time competition. Chronobiol Int, 2016; 33(6): 667-670

Shearer DA, Jones R, Kilduff LP, Cook CJ. Effects of competition on the sleep patterns of elite rugby union players. Eur J Sport Sci, 2015; 15(8): 681-686

Shearer DA, Kilduff LP, Finn C, Jones RM, Bracken RM, Mellalieu SD, Cook CJ. Measuring Recovery in Elite Rugby Players: The Brief Assessment of Mood, Endocrine Changes, and Power. Res Q Exerc Sport, 2015; 86(4): 379-386

Hursh S, Johnson M, Thorne D, Belenky G, Balkin T, Storm W, Miller J, Eddy D. Fatigue models for applied 
research in warfighting. Aviat Space Envir Md, 2004; 75(Suppl 3): A44-53

Thornton HR, Delaney JA, Duthie GM, Dascombe BJ. Effects of Pre-Season Training on the Sleep Characteristics of Professional Rugby League Players. Int J Sports Physiol Perform, 2017: 1-23

Van Dongen HP. Comparison of mathematical model predictions to experimental data of fatigue and performance. Aviat Space Environ Med, 2004; 75(3 Suppl): A15-36

Van Dongen HP, Maislin G, Mullington JM, Dinges DF. The cumulative cost of additional wakefulness: Dose-response effects of neurobehavioral functions and sleep physiology from chronic sleep restriction and total sleep deprivation. Sleep, 2003; 26(2): 117-126

West DJ, Finn CV, Cunningham DJ, Shearer DA, Jones MR, Harrington BJ, Kilduff LP. Neuromuscular function, hormonal, and mood responses to a professional rugby union match. J Strength Cond Res, 2014; 28(1): 194-200

Yarnell AM, Deuster P. Sleep As A Strategy For Optimizing Performance. J Spec Oper Med, 2016; 16(1): 81-85

\section{Corresponding author:}

\section{Ian Dunican}

Centre for Sleep Science, School of Human Sciences,

The University of Western Australia, Crawley, WA 6009, Australia.

Phone: 0409680867

Email: ian.dunican@meliusconsulting.com.au 